Stakkey, R. L., Jones, G. E. \& Frederick. L. R. (1956). J. gen. Microbiol. 15, 329-334

\title{
Effects of Medium Agitation and Wetting Agents on Oxidation of Sulphur by Thiobacillus thiooxidans
}

\author{
By R. L. STARKEY, G. E. JONES* AND L. R. FREDERICK† \\ Agricultural Experiment Station, New Brunswick, New Jersey, U.S.A.
}

SUMMARY: Thiobacillus thiooxidans oxidizes elemental sulphur more rapidly in a shaken than in static liquid medium. Various wetting agents either had little favourable effect or inhibited growth in static media at 100 p.p.m. In shaken media, some wetting agents were toxic, but 'Tergitol 08 ' and 'Tween 80 ' increased sulphur oxidation. 'Carbowaxes' and propylene glycol had relatively little effect on sulphur oxidation.

Oxidation of sulphur and growth of the strictly autotrophic chemosynthetic sulphur bacterium Thiobacillus thiooxidans are more rapid in early stages of development than later. This is due in part to inhibitory effects of the acid produced by oxidation of the sulphur (Starkey, 1925), but more to settling of the sulphur in the culture fluid. Most rapid oxidation in stationary media occurs when the sulphur is floating on the surface of the medium. The sulphur settles out as oxidation proceeds.

Since oxygen and carbon dioxide are required for growth and sulphur oxidation, development might depend on the amounts of these gases in the medium. Starkey (1925) noted that oxidation by growing cultures in static medium was greater when the air pressure was increased, but Vogler \& Umbreit (1941) found that at $\mathrm{pO}_{2}$ values from 10 to $30 \%$ and $\mathrm{pCO}_{2}$ values from 0.01 to $10 \%$ had little effect on oxidation. With resting cells, a $\mathrm{pO}_{2}$ value below that in air decreased oxidation of elemental sulphur somewhat and resulted in a greater decrease in oxidation of thiosulphate; oxidation was more rapid at increased $\mathrm{pO}_{2}$ values (Vogler, LePage, \& Umbreit, 1942).

The amount of sulphur surface in contact with the medium affects sulphur oxidation. The finer the particle size (Frederick \& Starkey, 1948; Starkey, 1925; Vogler \& Umbreit, 1941), the greater the concentration of sulphur (Frederick \& Starkey, 1948; Waksman \& Starkey, 1923), or the greater the amount of surface of liquid medium in contact with a unit of sulphur (Vogler \& Umbreit, 1941), the more rapid is the oxidation of sulphur.

This report gives the results of some studies on the effects of agitation and wetting agents on sulphur oxidation by Thiobacillus thiooxidans.

\section{METHODS}

A mineral salts medium (Starkey, 1925) containing elemental sulphur (flowers of sulphur) was used in $100 \mathrm{ml}$. portions in $250 \mathrm{ml}$. Erlenmeyer flasks. The results recorded are averages of two or more replicates. The incubation

* Present address: Scripps Institution of Oceanography, La Jolla, California, U.S.A.

$\dagger$ Department of Agronomy, Iowa State College, Ames, Iowa, U.S.A. 
temperature was $28^{\circ}$. Unless otherwise indicated, shaken flasks were incubated on a rotary shaker that made approximately 200 r.p.m. describing a circle about $5 \mathrm{~cm}$. in diam. The acidity of the culture solutions resulting from oxidation of sulphur to sulphate (titre) is the ml. $0.1 \mathrm{~N}$-alkali required to neutralize the acid in $5 \mathrm{ml}$. culture liquid.

The following wetting agents were tested: 'Tergitol Wetting Agent 08' (Aqueous solution, $\mathbf{3 8} \%$ ); sodium octyl sulphate, an anionic substance from the Carbide and Carbon Chemical Corp. 'Tween 80'; polyoxyethylene sorbitan mono-oleate, a non-ionic substance from the Atlas Powder Co.; 'Alconox' an alkyl naphthalene sulphonate with polyphosphate, an anionic substance from Alconox Inc.; 'Nacconol NRSF' an alkyl benzene sodium sulphonate, an anionic substance from the National Aniline Division; tri-ethylanolamine lauryl sulphate, a cationic substance from the Onyx Oil and Chemical Co.; 'Wetsit Conc' an alkylated aromatic sulphonate, an anionic substance from the Jacques Wolf and Co.

\section{RESULTS \\ Influence of shaking}

The results of one of six experiments on the effects of shaking on oxidation of sulphur are shown in Fig. 1. Sulphur was oxidized more rapidly in shaken media and the effect of shaking was greater the longer the incubation period. Similar results were obtained in all cases, but they varied quantitatively in that the finer the sulphur particles were the more rapid was the oxidation. Rotary shaking resulted in more rapid oxidation than reciprocal shaking, for in the latter case the sulphur accumulated in the necks of the flasks above the surface of the medium. In the stationary flasks practically all of the sulphur was suspended on the surface of the medium initially. This sulphur settled as the culture grew until, after 2 weeks, most of the unoxidized sulphur had settled. Oxidation of submerged sulphur is exceedingly slow in stationary media.

\section{Influence of wetting agents}

In most cases the wetting agents caused the sulphur to settle to the bottom of the flasks. This occurred with 'Tween 80', 'Nacconol', triethylanolamine lauryl sulphate (TLS), and 'Wetsit'. With 'Alconox' most of the sulphur settled. With 'Tergitol 08 ' most remained on the surface. The wetting agents had no effect on the $\mathrm{pH}$ values at the concentrations used. In static media there was no growth in the presence of 100 p.p.m. of 'Nacconol', 'TLS', or 'Wetsit' and very little growth in the presence of 'Alconox' or 'Tween 80' (Table 1). The culture developed normally in the medium with 'Tergitol 08'.

In shaken media the rate of oxidation of sulphur was increased by 'Tergitol 08 ' and 'Tween 80', and to some extent by 'Alconox'. The increase sometimes exceeded $100 \%$ with 'Tergitol 08 ' and 'Tween 80 '. 'Tergitol 08 ' had no effect at 10 p.p.m., but increased the oxidation rate at concentrations of 251000 p.p.m. (Fig. 2). An initial inhibitive effect of 1000 p.p.m. disappeared by the 12th day. 'Tween 80 ' increased the rate of sulphur oxidation at 50 and 


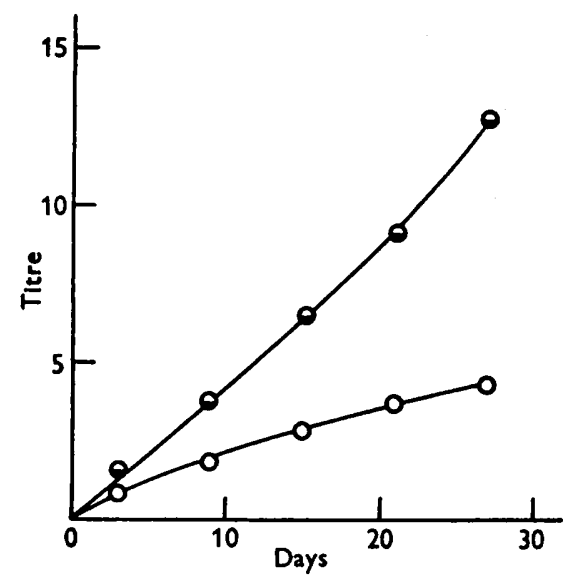

Fig. 1

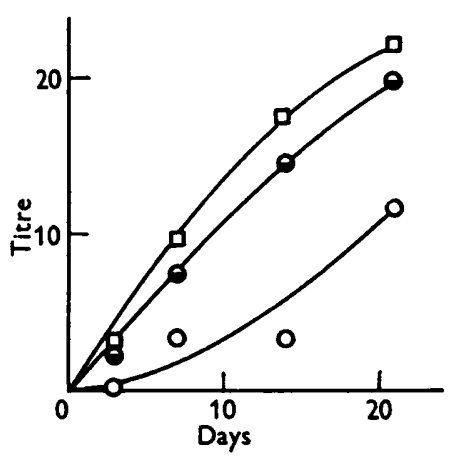

Fig. 3

Fig. 1. Oxidation of sulphur by Thiobacillus thiooxidans in shaken $(\ominus-\ominus)$ and static $(\mathrm{O}-\mathrm{O})$ media.

Fig. 3. Influence of 'Tween 80' on rate of oxidation of sulphur by Thiobacillus thiooxidans in shaken media. $\bigcirc-O$, control; $\odot-\Theta, 50$ p.p.m.; $\square \longrightarrow \square, 250$ p.p.m.

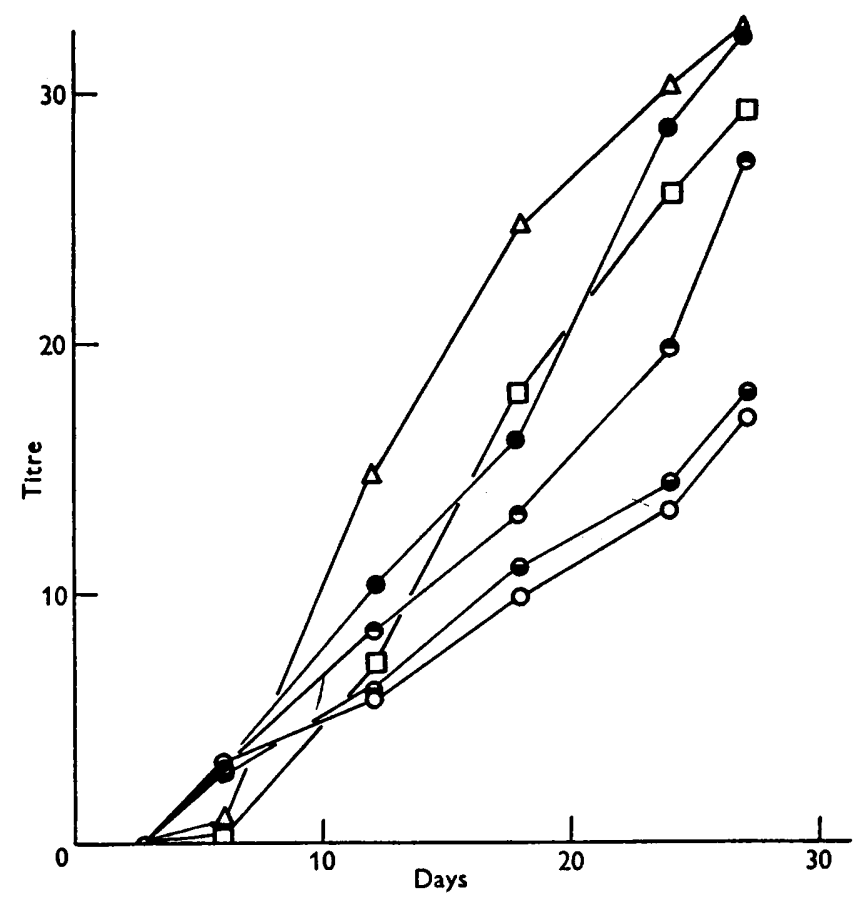

Fig. 2. Influence of concentration of 'Tergitol 08' on rate of oxidation of sulphur by Thiobacillus thiooxidans in shaken media. $\bigcirc-0$, control; $\Theta-\Theta, 10$ p.p.m.; $\ominus-\Theta$, 25 p.p.m.; $\bigcirc-100$ p.p.m.; $\triangle \longrightarrow \triangle, 500$ p.p.m.; $\square \longrightarrow \square, 1000$ p.p.m. 
250 p.p.m. (Fig. 3). Some increase was also noted with 'Alconox' at 25 and 100 p.p.m., but growth was inhibited completely at 500 p.p.m. (Table 2). 'Nacconol', 'TLS', and 'Wetsit' prevented growth at 100 p.p.m. in shaken as well as in stationary media.

Table 1. Influence of retting agents on sulphur oxidation by Thiobacillus thiooxidans in static media

\begin{tabular}{|c|c|c|c|c|c|c|c|c|}
\hline \multirow[b]{2}{*}{ Wetting agent } & \multirow{2}{*}{$\begin{array}{l}\text { Concn. } \\
\text { (p.p.m.) }\end{array}$} & \multicolumn{7}{|c|}{$\begin{array}{c}\text { Titre (see text) after various incubation } \\
\text { periods (days) }\end{array}$} \\
\hline & & 3 & 7 & 12 & 14 & 15 & 21 & 27 \\
\hline $\begin{array}{l}\text { Untreated } \\
\text { 'Alconox' }\end{array}$ & $\overline{100}$ & $\begin{array}{l}0 \cdot 8 \\
0\end{array}$ & - & $\begin{array}{l}\mathbf{2 \cdot 4} \\
\mathbf{0}\end{array}$ & - & $\begin{array}{l}2 \cdot 8 \\
0 \cdot 1\end{array}$ & $\begin{array}{l}3 \cdot 6 \\
0 \cdot 4\end{array}$ & $\begin{array}{l}4 \cdot 3 \\
0 \cdot 7\end{array}$ \\
\hline Untreated & 一 & $0 \cdot 3$ & 0.9 & - & $1 \cdot 4$ & - & $\mathbf{2} \cdot \mathbf{2}$ & - \\
\hline 'Tergitol 08'. & 100 & $0 \cdot 2$ & $1 \cdot 7$ & - & $\mathbf{2} \cdot \mathbf{3}$ & - & $2 \cdot 5$ & - \\
\hline 'Tergitol 08' & 500 & $\mathbf{0 \cdot 2}$ & $0 \cdot 6$ & - & $1 \cdot 2$ & - & $1 \cdot 3$ & - \\
\hline 'Tween 80' & $\mathbf{5 0}$ & $0 \cdot 1$ & $0 \cdot 2$ & - & $0 \cdot 5$ & - & 0.8 & - \\
\hline 'Tween 80' & 250 & $0 \cdot 1$ & $0 \cdot 2$ & - & 0.5 & - & $0 \cdot 8$ & $\ldots$ \\
\hline
\end{tabular}

Table 2. Influence of concentration of Alconox on rate of oxidation of sulphur by Thiobacillus thiooxidans in shaken media

Concn. of wetting agent (p.p.m.) Untreated 10

25 100 500

\begin{tabular}{cccccccc}
\multicolumn{7}{c}{ Titre after various incubation periods (days) } \\
\hline 3 & 6 & 9 & 12 & 15 & 18 & 24 & 27 \\
$0 \cdot 2$ & $1 \cdot 8$ & $2 \cdot 4$ & $2 \cdot 9$ & $3 \cdot 8$ & $4 \cdot 7$ & $7 \cdot 1$ & $9 \cdot 1$ \\
$0 \cdot 3$ & $2 \cdot 2$ & $2 \cdot 4$ & $3 \cdot 4$ & $4 \cdot 2$ & $5 \cdot 3$ & $7 \cdot 2$ & $8 \cdot 9$ \\
$0 \cdot 3$ & $4 \cdot 1$ & $4 \cdot 8$ & $5 \cdot 0$ & $7 \cdot 4$ & $9 \cdot 4$ & $10 \cdot 6$ & $12 \cdot 5$ \\
$0 \cdot 1$ & $0 \cdot 2$ & $0 \cdot 7$ & $2 \cdot 1$ & $3 \cdot 3$ & $4 \cdot 6$ & $11 \cdot 8$ & $15 \cdot 1$ \\
0 & 0 & 0 & 0 & 0 & 0 & 0 & 0
\end{tabular}

\section{Effects of certain glycols}

Brenner \& Owades (1954) reported that 'Carbowaxes' (polyethylene glycols) and propylene glycol dissolved sulphur and produced stable colloidal solutions of sulphur when poured into water. Because these materials might increase the solution of sulphur in the culture medium, the effects of 'Carbowax-200', 'Carbowax-600', and propylene glycol on sulphur oxidation were tested. They were mixed with sulphur, heated at $110-120^{\circ}$ for $15 \mathrm{~min}$. to dissolve the sulphur, and then added in appropriate amounts to sterile culture media containing the usual amounts of elemental sulphur. The media were inoculated and incubated on a rotary shaker. When the substances containing dissolved sulphur were added to the culture media, cloudy colloidal suspensions of sulphur were produced, but the medium became clear after the cultures had been incubated for a few days, which indicated that the suspensions were unstable. Though the rate of sulphur oxidation was increased somewhat, it is unlikely that the glycols increased the amount of sulphur in solution. We ascribe such favourable effects as were noted to increases in the amounts of finely divided sulphur in the media. 


\section{DISCUSSION}

Elemental sulphur was oxidized more rapidly in shaken than in stationary media. This agrees with results of Newburgh (1954) but disagrees with those of Umbreit (1951).

In practically no case did wetting agents increase oxidation of sulphur in static cultures, but they decreased it in some cases because of an effect other than toxicity. This is contrary to the observation (Vogler \& Umbreit, 1941) that sulphur which had settled out in media containing $0.001 \%$ aerosol was often oxidized more rapidly than sulphur on the surface. The smaller oxidation rates in static cultures where toxicity of the wetting agent was not involved was associated with settling of the sulphur to the bottom of the flask. The inhibitory effect can be attributed to deficiency of oxygen or carbon dioxide or both where the sulphur is submerged in the medium. The rate of oxidation in shaken cultures containing the wetting agents 'Tergitol 08 ' and 'Tween 80 ' not only exceeded that in static cultures containing no wetting agent, but even that in the untreated shaken medium. Since the surface of a sulphur particle that is wetted by the medium is that from which the bacterium derives sulphur, increase in the amount of wetted surface by wetting agents should and did result in more rapid sulphur oxidation.

There would be less opportunity for continued contact between cells of Thiobacillus thiooxidans and solid particles of sulphur in shaken than in static media. Nevertheless, the fact that oxidation was more rapid in shaken media does not exclude the possibility that sulphur oxidation depends on this contact. Through contact, a transportable sulphur substance might be produced enzymically on the cell surface, and the activity of the enzyme could be restored by the active cell. This implies a different means of sulphur uptake from that suggested by Umbreit, Vogel \& Vogler (1942), who contended that there was contact between the sulphur and fat contained in the bacterial cells. Knaysi (1943) opposed this theory on cytological grounds. The process seems improbable also because there is little likelihood of actual contact between the fat and sulphur; water films on the sulphur and cell wall would separate the two, and the cell wall itself, indicated by Knaysi (1943) and Umbreit \& Anderson (1942), would be an additional barrier.

This project was supported in part by a grant from the Texas Gulf Sulphur Company.

\section{REFERENCES}

Brenner, M. W. \& Owades, J. L. (1954). Stable colloidal sulfur solutions. Science, $119,911$.

Frederick, L. R. \& Starkey, R. L. (1948). Bacterial oxidation of sulfur in pipe sealing mixtures. J. Amer. Wat. Wks. Ass. 40, 729.

KNAYSI, G. (1943). A cytological and microchemical study of Thiobacillus thiooxidans. J. Bact. 46, 451.

Newburgh, R. W. (1954). Phosphorylation and chemosynthesis by Thiobacillus thiooxidans. J. Bact. 68, 93. 
Starkey, R. L. (1925). Concerning the physiology of Thiobacillus thiooxidans an autotrophic bacterium oxidizing sulfur under acid conditions. J. Bact. 10, 135.

UMBREIT, W. W. (1951). Significance of autotrophy for comparative physiology. In Bacterial Physiology, pp. 566-75, ed. Werkman, C. H. and Wilson, P. W. New York: Academic Press Inc.

Umbreit, W. W. \& ANDERson, T. F. (1942). A study of Thiobacillus thiooxidans with the electron microscope. J. Bact. 44, 317.

Umbreit, W. W., Vogel, H. R., \& VogLer, K. G. (1942). The significance of fat in sulfur oxidation by Thiobacillus thiooxidans. J. Bact. 43, 141.

Vogler, K. G., LePage, G. A. \& UMbreit, W. W. (1942). Studies on the metabolism of autotrophic bacteria. 1. The respiration of Thiobacillus thiooxidans on sulfur. J. gen. Physiol. 26, 89.

Vogler, K. G. \& UMBreit, W. W. (1941). The necessity for direct contact in sulfur oxidation by Thiobacillus thiooxidans. Soil Sci. 51, 331.

Waksman, S. A. \& Starkey, R. L. (1923). On the growth and respiration of sulfuroxidizing bacteria. J. gen. Physiol. 5, 285.

(Received 3 April 1956) 